\title{
Exploring Sustainable Value Creation of Industry 4.0 Technologies within the Socio-Technical Perspective: A meta-review
}

\author{
Emanuele Gabriel Margherita ${ }^{10000-0001-5528-6817]}$ and Alessio Maria Braccini ${ }^{1[0000-0002-}$ \\ 2004-4735] \\ ${ }^{1}$ University of Tuscia, Department of Economics Engineering Society and Organization - \\ DEIM, Via del Paradiso, 47, 01100, Viterbo, Italy \\ emargherita@unitus.it
}

\begin{abstract}
Our study examines how the topic of sustainable value creation of Industry 4.0 employs the social-technical perspective. Sustainable value creation of Industry 4.0 is an emerging topic in the IS literature. The topic extends the IT value, a core topic of IS, focusing on the sustainable outcome of these leading-edge technologies adopted into the assembly line of manufacturing organisations called Industry 4.0. We conducted a meta-review of three systematic literature reviews of this topic from which we extracted 23 empirical case studies. We address this gap employing the socio-technical framework. The study revealed that the technical perspective in prominent in literature, but socio-technical perspective studies exist. We further propose research directions to make more socio-technical the discourse.
\end{abstract}

Keywords: industry 4.0, sustainable value creation, sustainability, sociotechnical perspective; meta-review

\section{Introduction}

In 2019, Sarker et al. [1] launched a call to action for researchers and journals because the IS disciple is losing its distinctive trait - its axis of cohesion - the sociotechnical perspective. The socio-technical perspective conceives the organisation is composed of social and technical sub-systems and advocated that they require joint optimisation to operate. The resulted interplay among the two systems delivers positive outcomes for the organisations [2].

Our study follows this study examining how the topic of sustainable value creation of Industry 4.0 (I40) employs the social-technical perspective. This topic is an emerging trend within IS research. I40 is an umbrella term referring to a set of advanced technologies - the Internet of Things, Robotics, Big Data, and Cloud Manufacturing which are adopted into the assembly line within manufacturing organisations. The integration of I40 technologies deploys a programmable, interconnected cyberphysical system that automatically controls pieces of machinery in assembly lines. The way organisations use I40 technologies allows addressing the assembly line prob- 
lems without human interaction [3]. I40 technologies extend the IS research since they differ from traditional technologies studied in IS - e.g. ERP and CRM - targeting the operational activities rather than administrative ones and allows to study how organisations exploit production process information [4].

Effective adoption of I40 technologies delivers various IT value in terms of increasing production process, higher quality products, less natural resource usage, and improved workforce conditions [5, 6]. IT value of I40 technologies is often evaluated in sustainability terms employing the triple bottom line. The triple bottom line is an analytical framework that allows studying how organisations address the three dimensions of sustainability: economic, environmental, and social. Under this perspective, the study if IT value creation, which focuses only on the IT impacts of economic performance, is named Sustainable Value Creation (SVC), thus embracing the environmental and social implications of I 40 technologies.

To date, reviews summarised the SVC of I40 [7, 8] without assessing how the socio-technical perspective is employed. To address this gap, we make use of the sociotechnical perspective framework by Sarker et al.[1], which is composed of 6 groups representing six facets of the socio-technical perspective. In type I and II, the social perspective is predominant over the technical one. In contrast, the technical perspective is predominant over the social one in type V and VI. In type III, social and technical components are considered additively. Finally, type IV represents the traditional socio-technical perspective of IS.

Therefore, we performed a meta-review analysis of three systematic literature reviews focusing on SVC of I40 from which we extracted 23 empirical studies of SVC of I40. Our study mainly answers the research question: "How does the Sustainable Value Creation of Industry 4.0 research embrace the socio-technical perspective?"

The contribution to the literature is twofold. We explore how researchers employ the socio-technical perspective in the SVC of I40, and we propose future directions for researches to increase the use of the socio-technical perspective.

\section{Theoretical Framework}

This section presents the discourse of sustainable value creation of Industry 4.0, the socio-technical perspective, and the socio-technical perspective framework.

\subsection{Sustainable Value Creation of Industry 4.0}

Industry 4.0 refers to a new and powerful industrial wave oriented towards digital and virtual technologies and is service-centred. The term "Industry 4.0" is derived from the German "Industrie 4.0" initiative launched by the German government in 2011. It points to ensuring the future competitiveness of the German manufacturing industry [9]. The principles of Industry 4.0 are the horizontal and vertical integration of production systems driven by real-time data interchange and flexible manufacturing to enable customised production [10]. Vertical interconnection means across several 
departments within an enterprise, and horizontal interconnection expresses digital information sharing across several partners within a supply chain, including the customer.

Industry 4.0 builds on several technological developments. The most significant components of Industry 4.0 are cyber-physical systems, the internet of things, cloud manufacturing, and additive manufacturing [3, 11]. Cyber-physical systems allow organisations to integrate technologies enabling the self-decision making of technologies that afford to address mechanical issues without human interaction [3].

Industry 4.0 adoption is expected to deliver changes in economic, ecological, and social aspects [12,13], which forms the triple bottom line of sustainability [14]. The study of how I40 adoption delivers sustainable value is called SVC. The main question underpinning the SVC value debate is whether and under which conditions I40 adoption delivers sustainable value to organisations. SVC extends the IT value study, a long-standing debate in the IS literature, which engaged scholars for a long time investigating the potential economic benefits consequent to organisational investments in IT [15-17].

\subsection{Socio-Technical Theory}

Within the information systems literature, the Socio-technical perspective has introduced through two seminal articles by Bostrom and Heinen in the first MIS Quarterly, which presented the socio-technical theory $[2,18]$. The socio-technical theory devises the organisation composed of social and technical sub-systems. The former subsystem embraces workers, their roles, and their rules. The latter sub-system includes tasks and technologies for accomplishing organisational activities [1]. The sociotechnical perspective inherited the work system theory, which provides a perspective for understanding systems in organisations $[19,20]$.

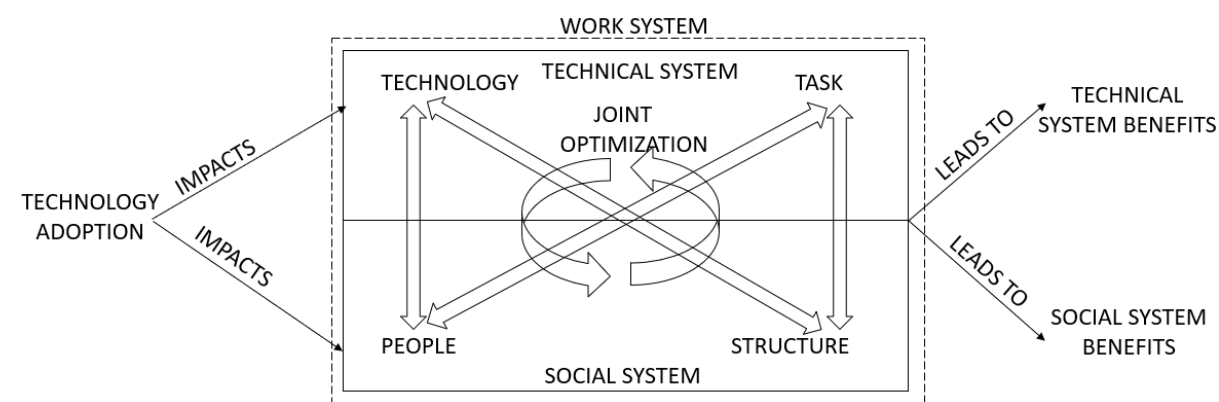

Figure 1 Socio-Technical Model (adapted from Bostrom \& Heinen, 1977a; Sarker et al., 2019)

Figure 1 depicts the socio-technical model to assess the organisational change triggered by technology adoption. The model views organisational systems as multivariate systems of two sub-systems, which are composed of four interacting and aligned components - task, structure, actor, and technology. During the technology adoption, socio-technical systems are open [21]. Therefore, systems need to adapt to their envi- 
ronment continuously to maintain the system state in equilibrium, where the four elements are mutually aligned.

The joint optimisation of both system stability involves stable relationships within and between the system components and its environment, which leads to improvements in both systems. In the technical systems, improvements concern a better performance and achieved economic objectives, whereas the ameliorations in the social system concern enhanced job satisfaction and higher quality of work-life [1, 22].

\subsubsection{Socio-Technical Framework}

After a systematic literature review, Sarker et al. 2019 concluded that IT studies employ the socio-technical perspective in various ways. There are studies which privilege the social perspective over the technical perspective and vice versa. And studies which additively considers social and technical components as outcome antecedents and the traditional socio-technical perspective. The authors summarised the results in a framework composed of 6 types of studies in Figure 2.
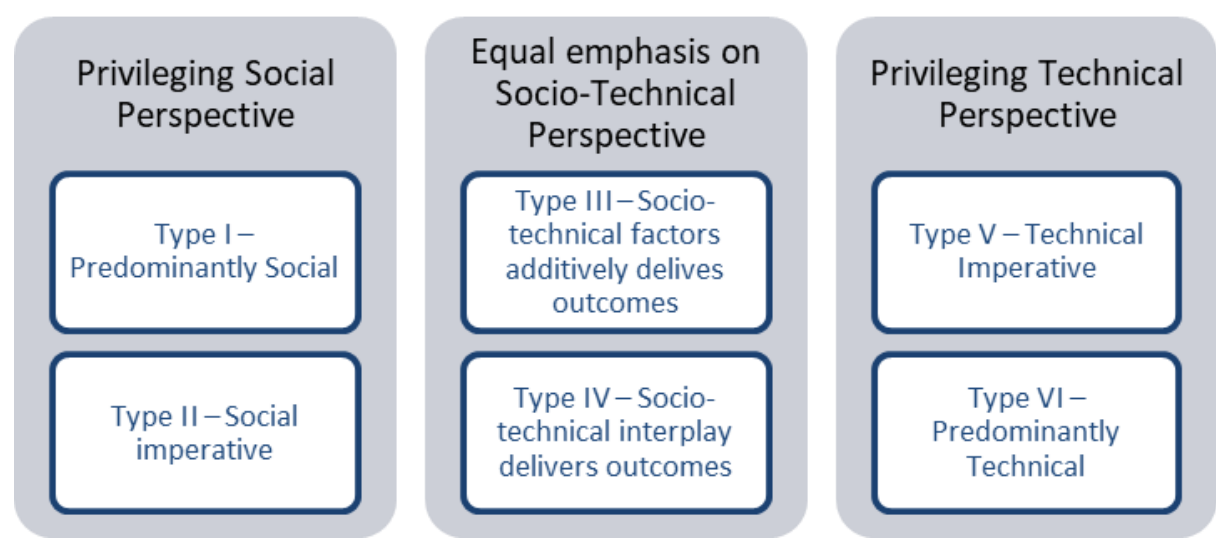

Figure 2 Socio-Technical Framework

Type I "Predominantly Social": this group refers to studies where the investigation focuses almost exclusively on the social (including psychological, sociological, economic, or philosophical) aspects related to the phenomenon of interest, with technological or informational considerations serving as the context. Social components are the main driver for the outcome.

Type II "Social Imperative": this group refers to studies that consider technology a product of human choice and action. This perspective is closely related to the notion of "organisational imperative," where social aspects influence technological artefacts and their outcome [23].

Type III "Socio-technical factors additively deliver outcomes." This group refers to studies where social and technological factors additively deliver outcomes. Technical and social components are enabling factors to outcomes but without any sort of interplay. 
Type IV "Socio-technical interplay delivers outcome": this group refers to studies where the socio-technical interplay clearly appears delivering outcomes. It is closest to the socio-technical perspective.

Type V "Technical Imperative": this group refers to studies where technology is a significant antecedent to social outcomes. In this conception, IT is viewed to bring structural, communicative, and decision-making changes in organisations a soft form of technological determinism.

Type VI "Predominantly Technical" group to studies where technology component is the sole precursor of the outcome. This body of knowledge is also known as design research in the IS discipline. Here, the focus is on how to develop or improve the technical component.

\section{Methodology}

Meta-review refers to an analysis that combines results from many individual systematic literature review studies addressing the same research question. It is a valuable methodology for research synthesis [24]. We chose this methodology since several literature reviews of SVC of I40 appeared over the last years. Thus a meta-review allows us to summarise the findings. And to assess the state-of-the-art of sociotechnical perspective of this topic. We performed a meta-review during February 2020. We searched literature review on SVC of I40 on Scopus and Google Scholar by the following keyword search: "industry 4.0" AND "literature review" AND "sustainability" OR "sustainab*" OR "sustainable value creation." We include the term sustainability because it is a close concept to SVC, and it is often used to indicate SVC outcome.

We limited the research within business and management studies and papers written in English. Scopus released 20 results. We read the title and abstract to check whether are literature review or different type of article - methodological, theoretical papers or literature review of diverse topics -. We include only literature reviews focusing on sustainability or SVC of I40 and excluding articles written in different languages from English. We reach a sample of 3 papers of systematic literature review. Therefore, we based meta-review on three literature reviews $[7,25,26]$. We thoroughly read the reviews extracting articles from references, which are empirical studies. We chose 23 empirical case studies of SVC in I40. We excluded the remaining paper since they are focused on different concepts. For instance, Piccarozzi et al. [26] review also I40 papers regarding production methods, business models or supply chain, while the remaining two literature reviews included several surveys or conceptual papers.

We examined empirical studies accordingly to the socio-technical framework [1], considering (1) how studies have enacted the presence of the social and the technical and (2) the relative outcomes. 


\section{$4 \quad$ Results}

In this section, we present the meta-review results providing descriptive statistics of the results and distinguishing the results by the socio-technical framework.

\subsection{Descriptive Statistics}

The result of the meta-review includes 23 studies that cover a period from 2014 to 2019. Figure 3 portrays the publication trend of the meta-review. According to our results, the year 2017 is the most productive with ten published papers of empirical I40 articles.

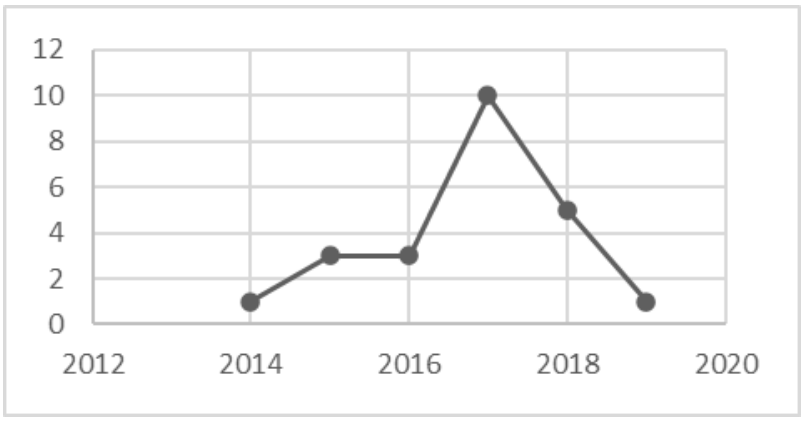

Figure 3 Publication trend of meta-review

The meta-review includes four conference proceedings studies, two articles from the journal sustainability while the remaining articles come from engineering and information systems journals. Table 1 depicts details of journal publication.

\begin{tabular}{|c|c|c|c|}
\hline Journal & $\begin{array}{l}\text { Nr. of } \\
\text { papers }\end{array}$ & Journal & $\begin{array}{l}\text { Nr. of } \\
\text { papers }\end{array}$ \\
\hline $\begin{array}{l}\text { Conference Proceedings } \\
\text { MECHANIKA. } \\
\text { Energies } \\
\text { Intern. Journal of Production Research } \\
\text { Intern. Journal of Innovation Management } \\
\text { AIChE Journal } \\
\text { Applied Science } \\
\text { Int. J. entrepreneurship sustainability } \\
\text { issues } \\
\text { Processes }\end{array}$ & $\begin{array}{l}4 \\
1 \\
1 \\
1 \\
1 \\
1 \\
1 \\
1 \\
1\end{array}$ & $\begin{array}{l}\text { Sustainability } \\
\text { Int. J. Agile Systems and Man } \\
\text { Research-Technology Management } \\
\text { Social Sciences } \\
\text { Int. Journal of Production Research } \\
\text { Int. J. of Distributed Sensor Net- } \\
\text { works } \\
\text { Cluster Computing } \\
\text { Engineering } \\
\text { Microprocessors and Microsystems } \\
\text { Int. J. Advanced manufacturing } \\
\text { techn. }\end{array}$ & $\begin{array}{l}2 \\
1 \\
1 \\
1 \\
1 \\
1 \\
1 \\
1 \\
1 \\
1 \\
1\end{array}$ \\
\hline
\end{tabular}

Table 1 Journal publication details

Figure 4 presents paper contributions by nations of the research team. China is the country which contributes with eight papers. Afterwards, we find European countries, especially Italy and Germany, contributing to an overall of 6 articles. We also saw 
three cross-country collaborations, namely, China and Canada, Estonia and Germany, and the UK and China.

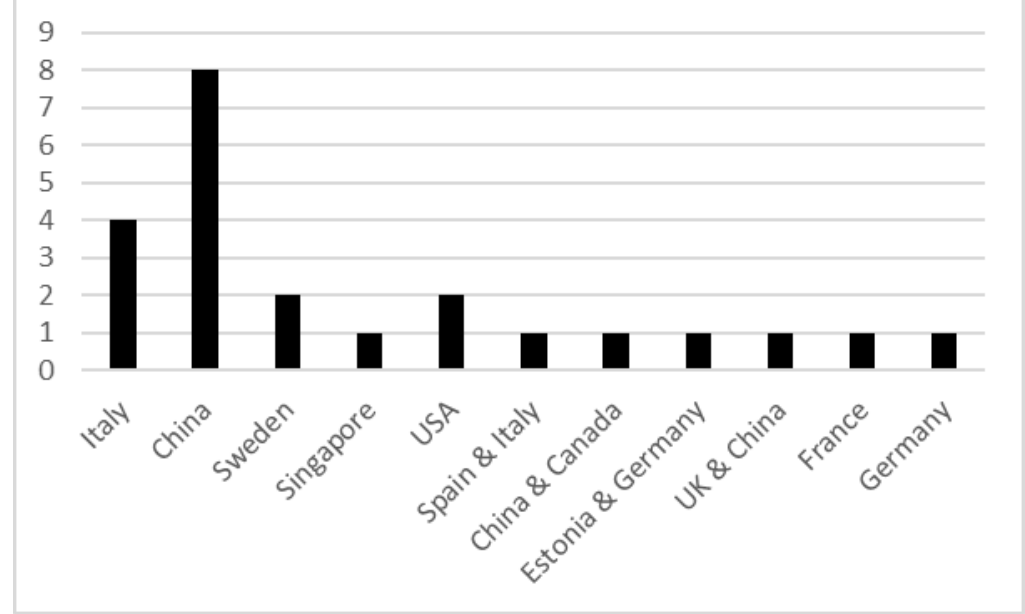

Figure 4 Research teams by nations

Figure 5 depicts the most used keywords in the keyword section of the articles. I40 is the most used keywords (twelve times), while SVC does not appear. Instead, the keyword sustainability appeared five times, together with the keywords sustainable manufacturing (two times) and triple bottom line (two times).

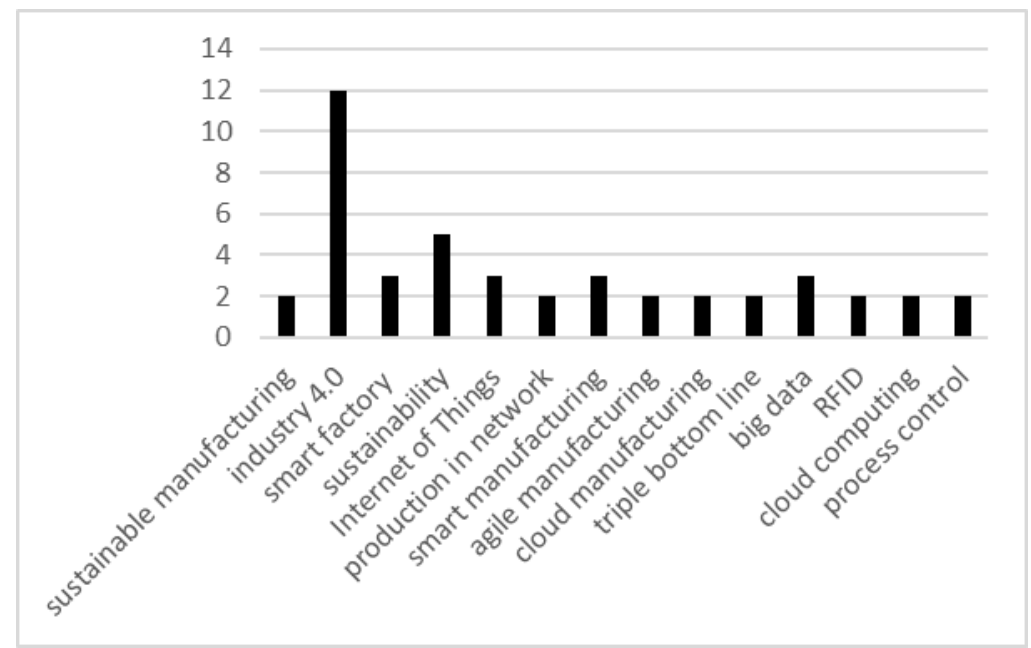

Figure 5 Most used keywords in the keyword section of the articles (count 2) 


\subsection{Results}

Figure 6 presents the results of the meta-review distinguishing papers by the sociotechnical framework. Sixteen studies pertain to type VI where technologies are the main driver for delivering outcomes [27-42].

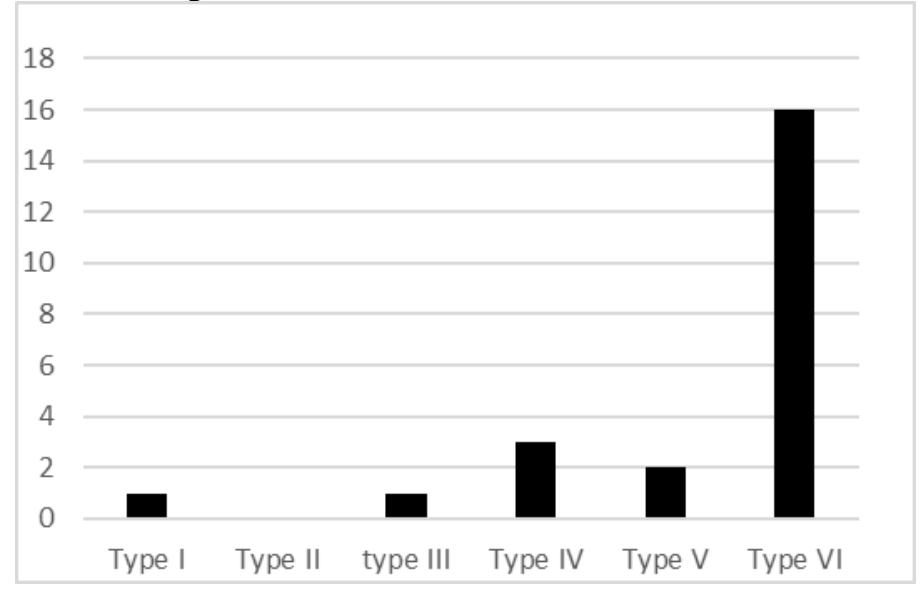

Figure 6 Proportion of studies in different categories

Studies are devoted to studying how to improve technologies to increase the technical system outcome on organisational performance. Within the group, we found three main categories: design of I40 technologies, integration of two or more I40 technologies, and the deployment of the smart factory through the cyber-physical system. The category of design of I40 technologies includes coding algorithms for big data to improve production efficiency, delivering economic value for organisations [39]. The category of integration of technology includes studies in which I40 technologies are implemented in organisational units. In these studies, the focus remains on technology issues without considering social aspects. The outcome of these studies is also on the social and environmental dimensions. For instance, [43] presents a study where IoT adoption allows optimising the assembly line of a sole company. The IoT adoption reduces faulty products and improving workforce conditions through the monitoring posture and pace of workers. The last category concerns the smart factory deployment, where is deployed the cyber-physical system [32, 37]. In these studies, the foci are on integration issues of technologies, business process reengineering, and how technology can communicate. The outcome presented in the studies is higher than the other groups. The deployment of cyber-physical systems allows to deliver sustainable value in higher efficiency; reduction of natural resource usage and safer workplace.

Type $5[44,45]$ considers researches where technology is the main driver for social outcomes. These studies present broad I40 adoptions where the main focus is on technologies creating a new way of production, which impacted social system delivering outcomes. For instance, Yuan et al. [45] present an I40 adoption transforming an oil refining and petrochemical plant into a connected and information-driven I40 plant environment. Using real-time and high-value support systems, I40 plant enables a coordinated and performance-oriented manufacturing enterprise. That responds quick- 
ly to customer demands minimising energy and material usage and increase safety at work automating unhealthy activities and monitoring plant status.

There is only one exemplary case for Type I [46], where users are the primary driver of I40 outcome. The case highlights managerial practices that allow I40 users to accommodate the acceptance of I40 technologies and their utilisation. Under this perspective, the study claims that I40 organisation should develop an organisational structure that provides users more autonomy through a matrix structure or a flat hierarchy. Moreover, leadership style should encourage an organisational climate for innovation and human resources practices - such as training courses or training on the jobs - that allows users to learn competences to use I40 technologies.

For Type 3 [8], we found exemplary studies where social and technical systems deliver benefits additively but without any sort of interplay. In the study [8], the authors present benefits and challenges of I 40 adoption for the delivery of sustainable value creation where social and technical parts contribute to the value creation but without considering their integration.

In type $4[12,47,48]$, there are the closest studies of the socio-technical perspective. The studies show the two sub-systems, the difficulties in the adoption process to reach the joint optimisations of sub-systems, and the socio-technical interplay whit consequent outcomes for both systems. In the study [12], I40 technologies are adopted in the assembly line where the low skilled workforce was employed. During the adoption, process technologies are integrated into the assembly line while the workforce attended vocational courses to work with technologies. The adoption was hard since I40 technologies required a workforce with higher informatic competences. The joint optimisation is reached where the workforce affords to use technologies which perform with a feasible speed. The socio-technical interplay concerns technologies producing the goods while the workforce supervises technologies and provides feedback to technology experts to maintain constant the production process. The study also explains that I 40 delivered sustainable value creation and therefore benefits in the two work systems. In the study [47], the socio-technical interplay exists when the workforce employs data to maintain constant production and fix mechanical issues. In this study, I40 adoption delivers an outcome for the environmental dimension supporting circular economy practices. In the study [48], authors present adoption details for the social and technical systems. While technologies are integrated and adopted into the I40 plants, the workforce is informed regarding the adoption. Also, they attended courses to use the technologies. The interplay exists when the workforce affords to analyse data that are effectively retrieved from technologies.

\section{$5 \quad$ Discussion \& Future Directions}

The results of the analysis show that the socio-technical perspective is not prominent within the SVC of I40.

From the descriptive analysis, we noted a lack of studies within the basket of eight IS core journals, which show that SVC in I40 is an emerging topic, but it is not a prominent area of high-quality research of IS. We encourage scholars to engage the 
topic of SVC of I40 for two main reasons. Firstly, SVC complements the IT value topic embracing the discourse of sustainability. It is currently required for IT technologies to create value not only on the economic performance of the organisation. But they have to create value for the organisations addressing both environmental and social issues. This shift towards the interest of financial outcome to sustainability outcome is already in place in the IS discourse. New topics emerged recently GREEN IS and ICT for sustainable development - in IS core conference, which includes track focusing on the sustainability of IS.

In contrast, others include sustainability as the core theme of the conference like ECIS 2020. Therefore, SVC topic allows for embracing sustainability topics holistically. Secondly, contrary to IS research, which mainly focused on ERP, CRM, and CSCW and how to exploit administrative data, I40 technologies are designed or equipped by sensors to acquire data regarding the production process. Therefore, I40 technologies pave the way to extend IS research exploring production process data generated [4].

Furthermore, I40 technologies allow exploring whether the building blocks of socio-technical systems have changed [49]. Similarly to the situation in which the researchers of Tavistock were to study the "longwall method" [50], I40 raised similar and more articulated concerns regarding the technology impact on the social systems within the production process since decision-making automation of technologies may supplant workforce activities. So far, these social aspects have not studied yet. Accordingly, for these reasons, we encouraged IS scholars to start analysing the topic of SVC of I40. Although the technical perspective is prominent in the review, we noticed these studies argued that there is a need to embrace the classical socio-technical perspective, including workers in the adoption process. For instance, Prause et al. [42] present a failure adoption of I40 where the main problems were the lack of social systems inclusion during the adoption.

Furthermore, we noticed that the technical perspective is prominent due to the early stage of I40 technologies. Most of the studies concentrate their effort to check the feasibility of I40 technologies, whether they can be developed and integrated. Therefore, to make the research more socio-technical, a turn is required from the focus of technology integration towards the adoption of technologies. The integration includes the implementation of only technical systems, while adoption includes the implementation phases where technical systems and social system are optimised to reach an effective utilisation.

Despite type III and IV focused on the technical and social outcome, the remaining studies consider the I40 adoption as a vehicle to reach technical outcomes without considering the social outcome, that is, I40 technologies that allow an efficient production process reducing energy usage. Further studies should link social goals from the beginning. This is twofold beneficial. Firstly, for a socio-technical point of view, it aims at the humanisation of the workplace, which is the first socio-technical purpose. Secondly, to embrace the social dimension of sustainability concerning organisational attitude to improve workforce condition, which is the less studied within the review. 
Finally, further studies should concentrate on investigating the remain sociotechnical concepts that remain unclear within the discourse of SVC of IS: the role of workers and where the socio-technical interplay exists in an I40 context. The few socio-technical studies of type IV group present workers - the primary user of I40 technologies - with a hybrid role between manual workers and maintenance workers while the interplay consists in the supervision of technologies or the analysis of data to address mechanical issues of technologies. However, these studies are not enough to shed light on these two concepts.

\section{Conclusions}

In the study, we analyse how studies employ the socio-technical perspective of the discourse of Sustainable Value Creation of Industry 4.0. We performed a meta-review of three systematic literature reviews selecting 23 empirical case studies, which became our research sample. The technical perspective is prominent in the literature. Thus we propose future directions of research to make the topic more socio-technical.

The study proposes implications for practitioners since they can use the metareview as a blueprint for I40 adoption and I40 integration to reach a sustainable value in which several best practices of I40 adoption and integration are highlighted. We acknowledge that the study has limitations. Based on three systematic literature reviews, there is the possibility to have omitted empirical case studies of SVC of I40.

\section{$7 \quad$ References}

1. Sarker S, Chatterjee S, Xiao X, Elbanna A (2019) The Sociotechnical Axis of Cohesion for IS discipline: its historical legacy and its continued relevance. MIS Q 43:695-719

2. Bostrom RP, Heinen JS (1977) MIS Problems and Failures: A Socio-Technical Perspective, Part II: The Application of Socio-Technical Theory. MIS Q 1:

3. Lee J, Bagheri B, Kao HA (2015) A Cyber-Physical Systems architecture for Industry 4.0-based manufacturing systems. Manuf Lett 3:18-23

4. Lasi H, Fettke P, Feld T, Hoffman M (2014) Industry 4.0. Bus Inf Syst Eng 6:239-242

5. Margherita EG, Braccini AM (2020) Industry 4.0 technologies in flexible manufacturing for sustainable organisational value: reflections from a multiple case study of italian manufacturers. Inf Syst Front

6. Margherita EG, Braccini AM (2020) Organisational impacts on sustainability of industry 4.0: a systematic literature review from empirical case studies. In: Agrifoglio R., Lamboglia R., Mancini D. RF (ed) Digital Business Transformation. Lecture Notes in Information Systems and Organisation,. Springer, Cham

7. Müller JM (2020) Industry 4.0 in the Context of the Triple Bottom Line of Sustainability: A Systematic Literature Review. In: Customer Satisfaction and Sustainability Initiatives in the Fourth Industrial Revolution. IGI Global

8. Kiel D, Muller JM, Arnold C, Voigt K (2017) Sustainable Industrial Value Creation: 
Benefits and Challenges of Industry 4.0. Int J Innov Manag 21:1740015

9. Kagermann H, Wolfgang W, Helbig J (2013) Recommendations for implementing the strategic initiative INDUSTRIE 4.0. Work Group Acatech, Frankfurt am Main, Ger

10. Thoben K-D, Wiesner S, Wuest T (2017) "Industrie 4.0" and Smart Manufacturing A Review of Research Issues and Application Examples. Internantional J Autom Technol 11:4-19

11. Kang HS, Lee JY, Choi S, et al (2016) Smart manufacturing: Past research, present findings, and future directions. Int J Precis Eng Manuf - Green Technol 3:111-128

12. Braccini AM, Margherita EG (2019) Exploring Organizational Sustainability of Industry 4.0 under the Triple Bottom Line: The Case of a Manufacturing Company. Sustainability 11:36. https://doi.org/10.3390/su11010036

13. Bednar PM, Welch C (2020) Socio-Technical Perspectives on Smart Working: Creating Meaningful and Sustainable Systems. Inf Syst Front 22:281-298

14. Elkington J (1997) Cannibals with forks - Triple bottom line of 21st century business. Stoney Creek, CT: New Society Publishers.

15. Melville N, Kraemer K, Gurbaxani V (2004) Information technology and organisational performance: An integrative model of it business value. MIS Q 28:283322

16. Braccini AM (2011) Value Generation in Organisations

17. Margherita EG, Braccini AM (2020) IS in the Cloud and Organizational Benefits: an Exploratory Study. In: Lazazzara A., Ricciardi F., Za S. (eds) Exploring Digital Ecosystems. Lecture Notes in Information Systems and Organisation, vol 33. Springer, Cham

18. Bostrom RP, Heinen SJ (1977) MIS Problems and Failures: A Socio-Technical Perspective. Part I: The Causes. MIS Q 1:

19. Alter S (2013) Work system theory: Overview of Core Concepts, Extensions, and Challenges for the Future. J Assoc Inf Syst 14:72-121

20. Von Bertalanffy L (1972) The History and Status of General Systems Theory. Acad Manag J 15:

21. Clegg CW (2000) Sociotechnical principles for system design. Appl Ergon 31:463477. https://doi.org/10.1016/S0003-6870(00)00009-0

22. Land F (2000) Evaluation in a Socio-Technical Context. In: in Baskerville, R., Stage, J., and DeGross, J.I., Organisational and Social Perspectives on Information Technology. Boston, Kluwer Academic Publishers

23. Markus L, Robey D (1988) Information Technology and Organizational Change: Causal Structure in Theory and Research. Manage Sci 34:583-598. https://doi.org/10.2307/2632080?ref=no-X-

route: $122 \mathrm{~d} 6 \mathrm{dd} 6 \mathrm{c} 03 \mathrm{f} 934528825 \mathrm{f} 5 \mathrm{a} 26 \mathrm{dba} 853$

24. Wu J, Lederer A (2009) A Meta-Analysis of the Role of Environment-Based Voluntariness in Information Technology Acceptance. MIS Q

25. Kamble SS, Gunasekaran A, Gawankar SA (2018) Sustainable Industry 4.0 framework: A systematic literature review identifying the current trends and future perspectives. Process Saf Environ Prot 117:408-425

26. Piccarozzi M, Aquilani B, Gatti C (2018) Industry 4.0 in Management Studies: A $\begin{array}{llll}\text { Systematic } & \text { Literature } & \text { Review. } & \text { Sustainability }\end{array}$ 
https://doi.org/10.3390/su10103821

27. Yue X, Cai H, Yan H, et al (2015) Cloud-assisted industrial cyber-physical systems: An insight. Microprocess Microsyst 39:1262-1270. https://doi.org/10.1016/j.micpro.2015.08.013

28. Yang C, Lan S, Shen W, et al (2017) Towards product customisation and personalisation in IoT-enabled cloud manufacturing. Cluster Comput 20:1717-1730. https://doi.org/10.1007/s10586-017-0767-x

29. Yang S, Raghavendra MRA, Kaminski J, Pepin H (2018) Opportunities for industry 4.0 to support remanufacturing. Appl Sci 8:. https://doi.org/10.3390/app8071177

30. Gu F, Guo J, Hall P, Gu X (2018) An integrated architecture for implementing extended producer responsibility in the context of Industry 4.0. Int J Prod Res ISSN

31. Lao L, Matthew E, Christofides PD (2014) Smart Manufacturing: Handling Preventive Actuator Maintenance and Economics Using Model Predictive Control. AIChE J 60:

32. Pei F, Tong Y, He F, Li D (2017) Research on design of the smart factory for forging enterprise in the industry 4.0 environment. Mechanika 23:146-152. https://doi.org/10.5755/j01.mech.23.1.13662

33. Waibel MW, Steenkamp LP, Moloko N, Oosthuizen GA (2017) Investigating the Effects of Smart Production Systems on Sustainability Elements. Procedia Manuf 8:731-737. https://doi.org/10.1016/j.promfg.2017.02.094

34. Gregori F, Papetti A, Pandolfi M, et al (2018) Improving a production site from a social point of view: an IoT infrastructure to monitor workers condition. Procedia CIRP 72:886-891

35. Shiyong Wang, Jiafu Wan, Di Li, Chunhua Zhang (2016) Implementing Smart Factory of Industrie 4.0: An Outlook. Int J Distrib Sens Networks 2016:1-10

36. Theorin A, Bengtsson K, Provost J, et al (2017) An event-driven manufacturing information system architecture for Industry 4.0. Int J Prod Res 55:1297-1311. https://doi.org/10.1080/00207543.2016.1201604

37. Rauch E, Dallasega P, Matt DT (2017) Distributed manufacturing network models of smart and agile mini-factories. Int $J$ Agil Syst Manag 10:185-205. https://doi.org/10.1504/ijasm.2017.10009457

38. Qu T, Lei SP, Wang ZZ, et al (2016) IoT-based real-time production logistics synchronisation system under smart cloud manufacturing. Int J Adv Manuf Technol 84:147-164. https://doi.org/10.1007/s00170-015-7220-1

39. Moyne J, Iskandar J (2017) Big data analytics for smart manufacturing: Case studies in semiconductor manufacturing. Processes 5:. https://doi.org/10.3390/pr5030039

40. Zhang Y, Liu S, Liu Y, et al (2018) The 'Internet of Things' enabled real-time scheduling for remanufacturing of automobile engines. J Clean Prod 185:562-575

41. Wang C, Jiang P, Ding K (2017) A hybrid-data-on-tag-enabled decentralised control system for flexible smart workpiece manufacturing shop floors. Proc Inst Mech Eng Part C J Mech Eng Sci 231:764-782. https://doi.org/10.1177/0954406215620452

42. Prause G, Atari S, Prause G, Atari S (2017) On sustainable production networks for Industry 4.0. Entrep Sustain Issues, Entrep Sustain Cent 4:421-431

43. Gregori F, Papetti A, Pandolfi M, et al (2017) Digital Manufacturing Systems: A Framework to Improve Social Sustainability of a Production Site. Procedia CIRP 63:436-442. https://doi.org/10.1016/j.procir.2017.03.113 
44. Garcia-Muiña FE, González-Sánchez R, Ferrari AM, Settembre-Blundo D (2018) The paradigms of Industry 4.0 and circular economy as enabling drivers for the competitiveness of businesses and territories: The case of an Italian ceramic tiles manufacturing company. Soc Sci 7:. https://doi.org/10.3390/socsci7120255

45. Yuan Z, Qin W, Zhao J (2017) Smart Manufacturing for the Oil Refining and Petrochemical Industry. Engineering 3:179-182

46. Shamim S, Cang S, Yu H, Li Y (2017) Examining the feasibilities of Industry 4.0 for the hospitality sector with the lens of management practice. Energies 10:. https://doi.org/10.3390/en10040499

47. Bressanelli G, Adrodegari F, Perona M, Saccani N (2018) Exploring How UsageFocused Business Models Enable Circular Economy through Digital Technologies. Sustainability. https://doi.org/10.3390/su10030639

48. Sjödin DR, Parida V, Leksell M, Petrovic A (2018) Smart Factory Implementation and Process Innovation: A Preliminary Maturity Model for Leveraging Digitalisation in ManufacturingMoving to smart factories presents specific challenges that can be addressed through a structured approach focused on people, p. Res Technol Manag 61:22-31. https://doi.org/10.1080/08956308.2018.1471277

49. Margherita EG, Braccini AM (2020) Exploring the socio-technical interplay of Industry 4.0: a single case study of an Italian manufacturing organisation. In: Proceedings of the 6th International Workshop on Socio-Technical Perspective in IS Development (STPIS 2020), June 8-9, 2020. CEUR Workshop Proceedings (CEURWS.org)

50. Trist EL, Bamforth KW (1951) Some Social and Psychological Consequences of the Longwall Method of Coal-Getting. Hum Relations 4: 